\title{
Roll-to-roll printed and assembled large area LED lighting element
}

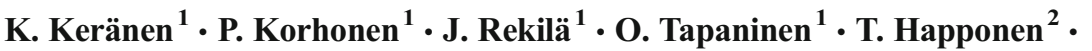 \\ P. Makkonen ${ }^{3} \cdot$ K. Rönkä ${ }^{1}$
}

Received: 24 November 2014 / Accepted: 28 April 2015 / Published online: 10 May 2015

(C) The Author(s) 2015. This article is published with open access at Springerlink.com

\begin{abstract}
Novel continuous and mass customizable lightemitting diode (LED) lighting foil system, capable to produce adequate lighting levels for general lighting, was designed, processed, and characterized. Lighting element substrate was processed by roll-to-roll (R2R) printing using silver ink and automatic bonding of LEDs and current regulators on polyethylene terephthalate (PET) substrate using isotropic conductive adhesive (ICA). Demonstrator consisting of two basic lighting elements contained 98 LEDs and produced $860 \mathrm{~lm}$ when running with $25 \mathrm{~mA}$ operational current through the LEDs when using total electrical driving power of $8.4 \mathrm{~W}$. Measured power
\end{abstract}

Manuscript was submitted at 24th of November 2014 for review. This work was supported in part by Painettavan Paalutus 2013 project, which was mainly funded by TEKES - the Finnish Funding Agency for Technology and Innovation.

K. Keränen

kimmo.keranen@vtt.fi

P. Korhonen

Pentti.korhonen@vtt.fi

J. Rekilä

jari.rekila@vtt.fi

O. Tapaninen

olli.tapaninen@vtt.fi

T. Happonen

tuomas.happonen@ee.oulu.fi

P. Makkonen

pekka.makkonen@flexbright.fi

K. Rönkä

kari.ronka@vtt.fi

$1 \quad$ VTT, Kaitoväylä 1, 90570 Oulu, Finland

2 University of Oulu, Erkki Koiso-Kanttilan katu 3, 90570 Oulu, Finland

3 Flexbright, Lentolantie 23, 36200 Kangasala, Finland conversion efficiency of the demonstrator was $31 \%$ and efficacy $102 \mathrm{~lm} / \mathrm{W}$. Element produced $460 \mathrm{~lx}$ illumination level measured by an illumination level meter at element's central axis at distance of $1 \mathrm{~m}$. At a distance of $2 \mathrm{~m}$, illumination level was $110 \mathrm{~lx}$, respectively. Temperature measurements with T3Ster thermal characterization instrument showed that when driving LED with maximum nominal driving current of $100 \mathrm{~mA}$, LED junction temperature was about $120^{\circ} \mathrm{C}$, when lighting element was in air in room temperature. Accelerated environmental stress tests consisting of 500 cycles from $-40 \ldots+80{ }^{\circ} \mathrm{C}$ in aging oven and $1000 \mathrm{~h}$ in $+60{ }^{\circ} \mathrm{C} / 95 \% \mathrm{RH}$ climate chamber were performed to test samples without any failures. In addition, over 700 bending cycles using $20 \mathrm{~mm}$ bending radius were performed to test samples without any failures, so bonding of LEDs were shown reliable according to these tests. Achieved results proved that thin, flexible, and large area high luminous flux lighting elements and systems can be processed based on plastic foil manufactured using R2R silver ink printing and $\mathrm{R} 2 \mathrm{R}$ automatic bonding of LEDs and regulator components using ICA on that foil.

Keywords Continuous foil system · Mass customizable foil system $\cdot$ Roll-to-roll printing $\cdot$ Roll-to-roll assembly $\cdot$ Polymer substrate $\cdot$ Large area LED lighting foil $\cdot$ Thermal management

\section{Introduction}

Several applications are pursuing thin, flexible, and large area platform for signage and lighting solutions. Large area flexible electronics technology provides an attractive possibility for making flexible lighting devices to be utilized in flexible or conformal lighting applications. Technology enables manufacturing of very thin, potentially large area lighting elements that can be bent and shaped and enable curved forms for 
more design freedom. Organic light-emitting diodes are a wellknown example of such large area electronics-based luminaires [1-3]. However, there are four main problems that are commonly considered as the limiting factors for the OLED commercialization for the next 5-10 years [4], i.e., emissive area, cost, efficiency, and lifetime. Flexible lighting devices can also be made using a multitude of inorganic LEDs divided over the foil surface at a regular spacing [5-8]. A diffuser can be added to homogenize the light when needed [8]. In addition, it is possible to enlarge LED's point source of light-emitting surface using specific collimator optics on top of LED and apply collimator optics output surface with a foil with optical structures diffusing collimated light again [9]. It is beneficial to integrate the LEDs onto the foil in their unpackaged form as this saves packaging cost [10] and keeps the total assembly thickness low, thus ensuring flexibility of the assembly. Cost-effective thin foils such as polyethylene terephthalate (PET) are preferably used as substrate material, since this can reduce the substrate costs by up to a factor of 10 [11], compared to conventional polyimide (PI) foil. The use of PET, however, creates some processing challenges, because it has a much lower thermal stability than PI [12]. This introduces limitations for the integration technologies that can be used [13-15]. For instance, conventional solder materials cannot be used with PET. PET and similar low-cost materials do not endure the conventional soldering temperatures, so adhesives or low-temperature solders must be used in bonding of components. Lowtemperature soldering with tin-bismuth- or tin-indium-based solders, however, requires relatively long (few minutes) soldering profile at relatively high peak temperatures $\left(140-160{ }^{\circ} \mathrm{C}\right)$. Low melting temperatures such as $118{ }^{\circ} \mathrm{C}$ for $52 \mathrm{In} 48 \mathrm{Sn}$ or $138{ }^{\circ} \mathrm{C}$ for $58 \mathrm{Bi} 42 \mathrm{Sn}$ can also represent a severe problem in LED luminaire applications, where relatively high local peak temperatures can occur in LEDs, causing re-melting of the interconnections. Conductive adhesive bonding is a technology that is compatible with PET substrates [13-14]. Two classes of conducting adhesives can be used [16], anisotropic conductive adhesives (ACAs) and isotropic conducting adhesives (ICAs) in electrical bonding. ACAs are typically used for bonding RFID chips and have the advantage that they can be deposited over the whole bonding area, due to their anisotropic conductive nature. ICAs conduct electricity in all directions, and adhesive dots need to be precision screen printed exactly onto the substrate bonding pads, but have been proven to be a reliable low-temperature processing compatible bonding material [17]. To improve the durability of the ICA bond, a glob top encapsulant or underfill adhesive material is often added, since the bond area of the ICA joint is relatively small. In addition, it is possible to utilize non-conducting adhesives (NCA) in order to ensure mechanical bonding. Next to short-timescale temperature limitations for processing, a temperature restriction of around $75{ }^{\circ} \mathrm{C}$ also applies for long-term reliability, due to the glass transition temperature of the PET material.
Furthermore, assembled LED dies can fail from a temperature shock and thermo-mechanical stresses during operation [17]. Therefore, heat management design of the LED assembly needs to be optimized, to ensure that the die, bonds, and foil temperatures are kept within operational limits to ensure reliable operation of the component.

Two small-scale flexible lighting technology demonstrators utilizing LED chips have been introduced during the latest couple of years. Technology demonstrator consisting of six modules of $5 \times 5$ array of $5-\mathrm{mm}$ spaced blue LED chips on silver ink printed multilayer PC foil structure has been introduced [8]. Another example is a structure consisting of $8 \times 8$ LEDs of 8 -mm spaced blue LED chips on single-layer copper-PET foil has been introduced [18].

Both aforementioned state-of-the-art lighting foil demonstrators based on inorganic blue LED chips have been processed in sheet-to-sheet (S2S) process. However, large area R2R hybrid integration manufacturing technology combining $R 2 R$ printing, $R 2 R$ assembly, and $R 2 R$ lamination is required for enabling high-volume and cost-efficient manufacturing of flexible lighting foil for effective commercialization of inorganic LED component or bare die or based flexible lighting foil.

We have developed and demonstrated hybrid manufacturing technology combining R2R printing and inorganic LEDs R2R assembly utilizing PET substrate capable to provide adequate illumination levels for general lighting. Until now, it has been unsure, if it is possible to produce enough luminous power based on large area flexible printed substrates required in general lighting applications. The main challenge blocking the utilization of low-cost polymer substrates, such as PET, PEN, and PC has been the thermal management issue with these substrate materials. These materials have typically low thermal conductivity causing potential heat management challenge, when lot of illumination power is needed. It is a necessity to guarantee proper operational temperature for the LED, in order to ensure reliable operation and long lifetime for the LED. Safe maximum intrinsic operational temperature of the LED die is typically specified to be $120-130{ }^{\circ} \mathrm{C}$ according to the LED manufacturers. We have demonstrated solution in which total thermal load is divided in many points facilitating safe operation of LEDs due to the fact that intrinsic temperature of LEDs is limited to $120{ }^{\circ} \mathrm{C}$. Thermal management of LED on PET foil can be improved further by implementing special heat management structures in the LED bonding areas, such as thermal vias and slugs, to conduct the excess heat through the poor thermal conductivity PET material to the heat sink [19].

We have experimentally demonstrated a continuous, mass customizable large area LED lighting element based on R2R printed PET substrate capable to provide adequate 
illumination levels for general lighting. This mass customizable lighting system is modular both along the printing machine direction (MD) and can also be cut in one to seven strips in printing machine cross direction (CD). This novel continuous and mass customizable LED lighting foil implementation enables cutting of variable size large area LED lighting elements all operating using $24 \mathrm{VDC}$.

\section{Design and implementation of large area, continuous, and mass customizable lighting system}

Demonstrated LED lighting element is based on R2R printing of conductive silver ink (Asahi 411 AW) and dielectric Henkel/Acheson (Electrodag 452SS and Electrodag $\mathrm{PF} 455 \mathrm{~B})$ patterns printed to form continuous and mass customized wiring board on 125- $\mu$ m-thick PET Melinex ST506 substrate. Continuous and mass customized wiring board was enabled by special wiring layout design and printing technique so that crossing sections of wiring conduits were enabled without short circuit by printing dielectric pattern between lower conductor and upper conductor patterns in crossing sections of continuous wiring (see Fig. 1).

In practice, printing was performed in four runs. First, pattern 1 was printed using Asahi 411AW silver ink. Second, pattern 2 was printed using silver ink, also. Third, pattern 3 was printed using Electrodag 452SS dielectric ink. Electrodag PF455B performance was tested, also, in this pattern. Forth, pattern 4 was printed using silver ink to form continuous bus lines for power supply. Printing sequences are shown in Fig. 2.

Continuous wiring board was printed by MAXI pilot printing machine equipped with gravure, flexography, and rotary screen printing units (Fig. 3).

Main specifications of MAXI pilot printing machine are listed as follows:

- Four interchangeable printing unit slots

- Forward and reverse gravures

- Rotary silk screen

- Flexography

- Slot die coating

- Plasma substrate treatment unit

- Lamination unit

- R2R hot embossing unit

- Die cutting unit

- Drying units (air, UV)

- Automatic registration system

- Max. web width $300 \mathrm{~mm}$

- Max. web velocity $30 \mathrm{~m} / \mathrm{min}$
MAXI machine main processing details are listed as follows:

- Hot air drying unit after each printing unit slot

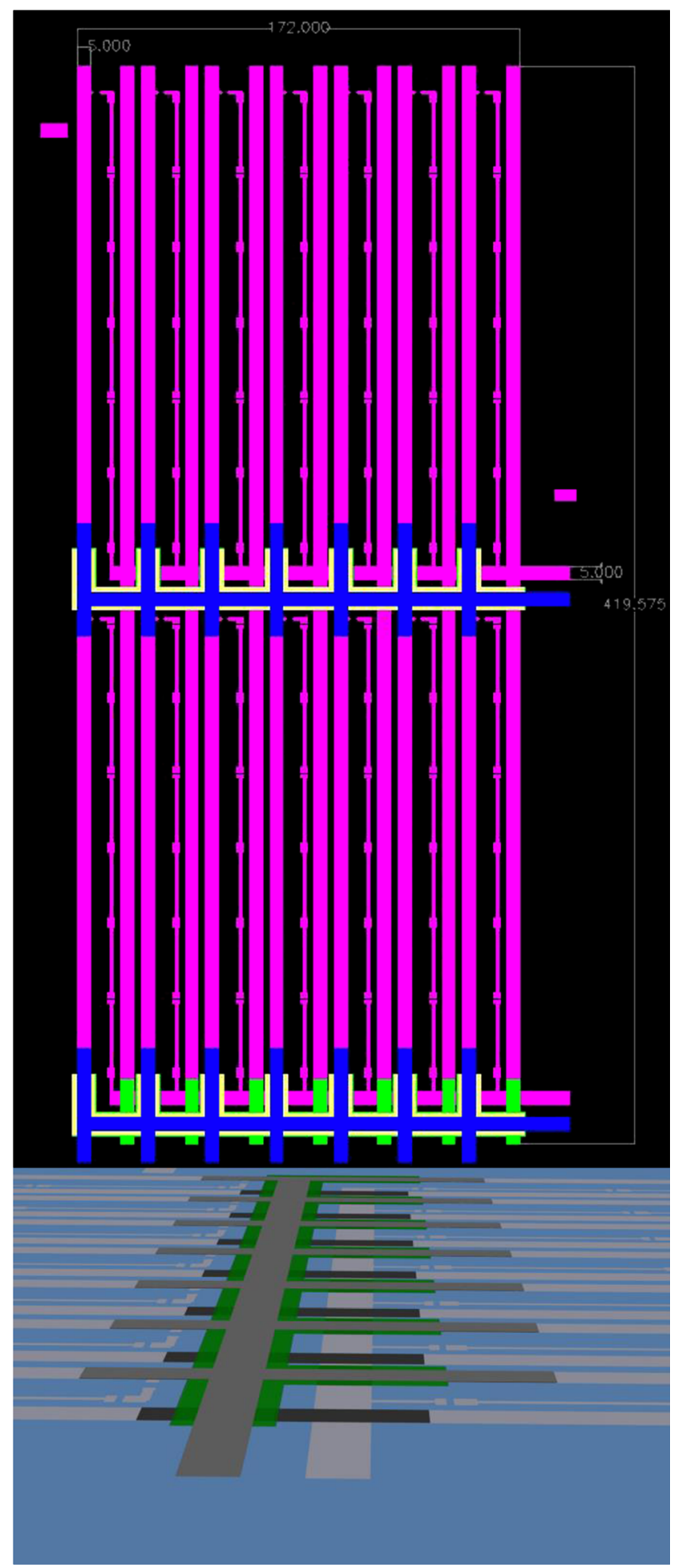

Fig. 1 Continuous and mass customizable LED lighting substrate layout design (above), length of system $419.575 \mathrm{~mm}$, width $172 \mathrm{~mm}$, and width of conductive traces $5 \mathrm{~mm}$. Detail of designed printing layers (below) 


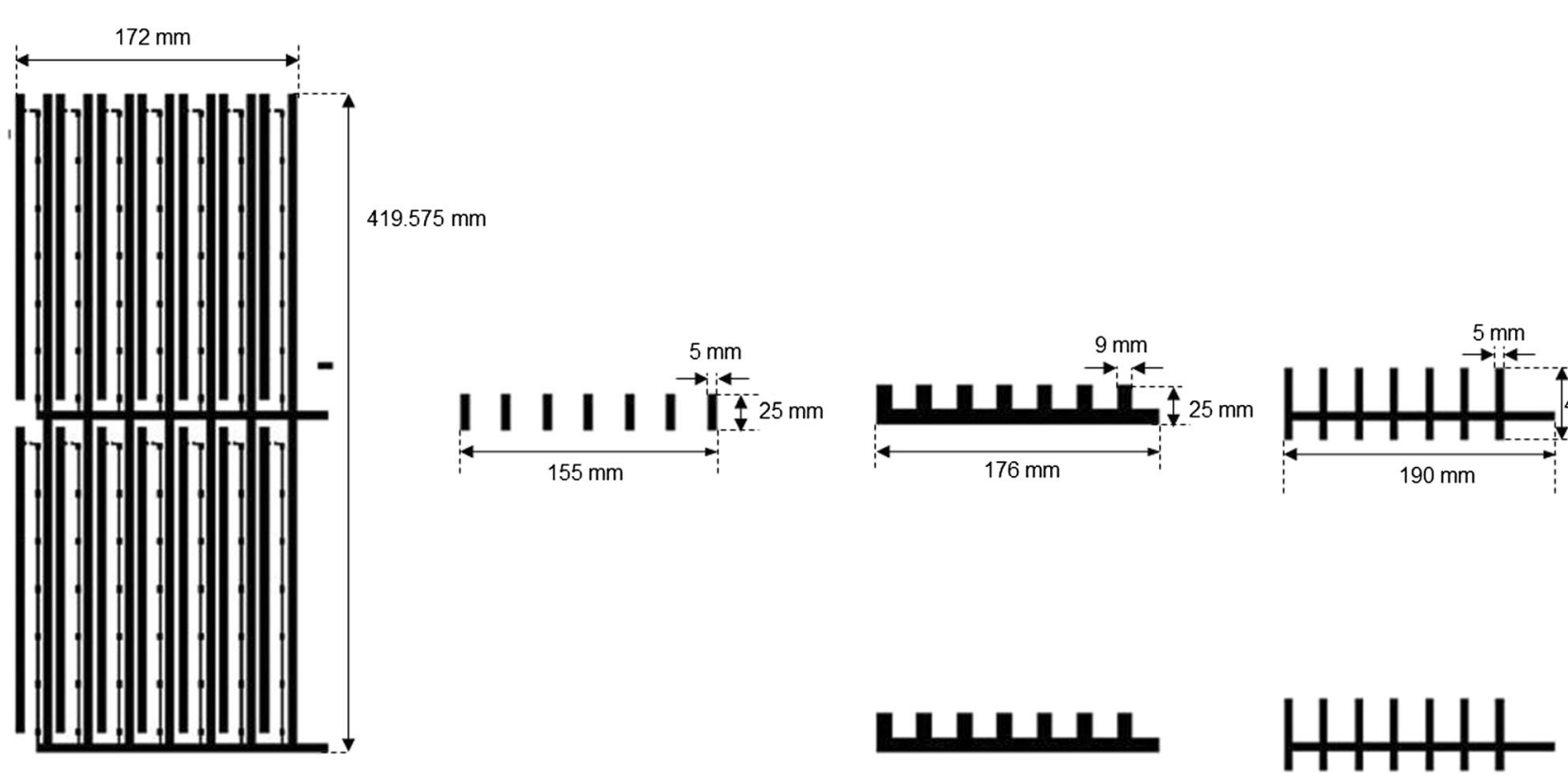

Fig. 2 Four pattern printing sequences to process continuous and mass customizable LED lighting element wiring board

- $\quad$ Length $3 \mathrm{~m}$

- Maximum temperature $180{ }^{\circ} \mathrm{C}$

- Maximum air inflow $600 \mathrm{~m}^{3} / \mathrm{h}$ (only on the topside of substrate)

- Drying units (air, UV)

- Automatic registration system

- Registration accuracy down to $\pm 50 \mu \mathrm{m}$

- Roll can be processed several times through the line if needed

- Detects also transparent layers like ITO

- $\quad$ Printing on plastic and paper substrates

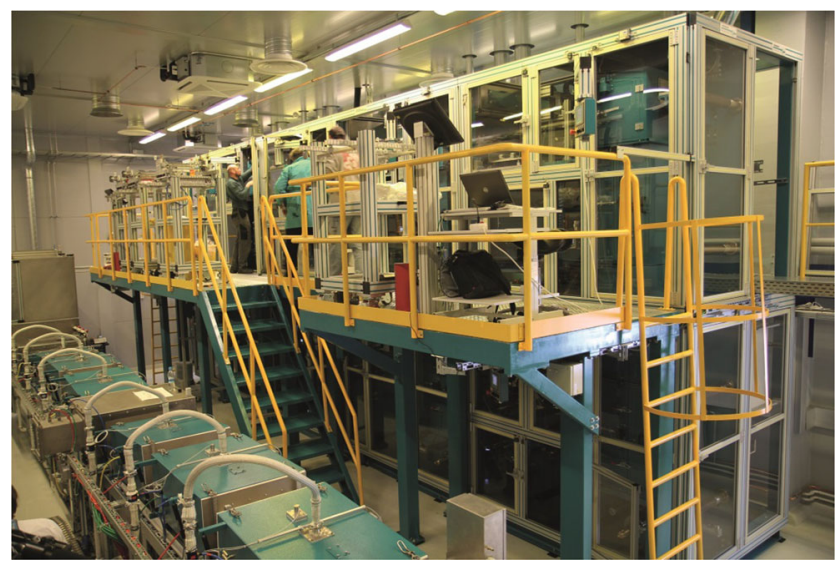

Fig. 3 MAXI roll-to-roll pilot printing machine used in the printing of the conductive traces on continuous and mass customizable LED lighting foil substrate
- Substrate thickness from 10 to $500 \mu \mathrm{m}$

- Diameter of rollers in winder units is $76.2 \mathrm{~mm}$

- Maximum web width $300 \mathrm{~mm}$

- Maximum printing width $260 \mathrm{~mm}$

- Also possible to use narrower webs

- Repeat length $409.575 \mathrm{~mm}$

- Web tension 25-250 N

- Several tension sensing rollers in critical positions through the line

- Web velocity range $0.1-30 \mathrm{~m} / \mathrm{min}$

Printing of silver ink pattern 1 was performed using MAXI rotary screen printing unit 1 . Gallus RVS screen mesh 275 was

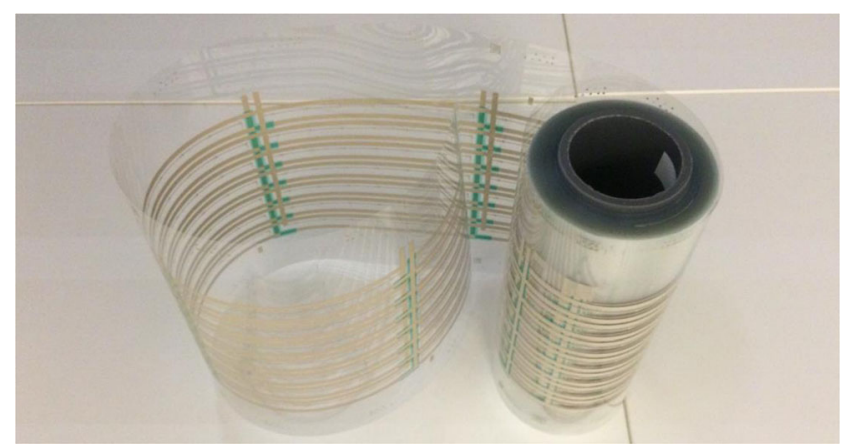

Fig. 4 Processed continuous and mass customizable R2R printed wiring board for flexible large area LED lighting system. Wiring board sample length $50 \mathrm{~m}$, roll width $300 \mathrm{~mm}$, wiring area total width $190 \mathrm{~mm}$, substrate thickness $125 \mu \mathrm{m}$, printed conductive trace thickness $13 \mu \mathrm{m}$ 


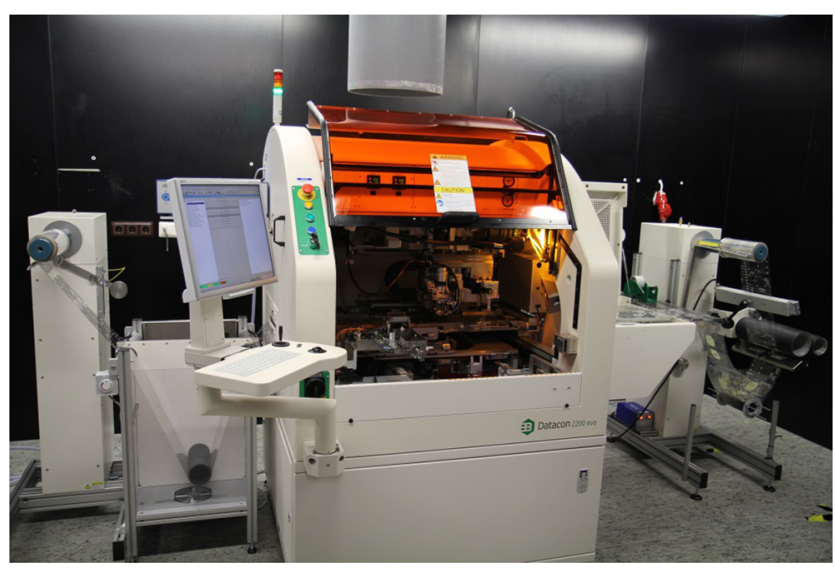

Fig. 5 EVO 2200 automatic R2R bonding machine

used in printing. Printing speed was $2 \mathrm{~m} / \mathrm{min}$, and two hot air dryers temperature of $140{ }^{\circ} \mathrm{C}$ were used for ink sintering. Pattern 2 was printed using MAXI rotary screen printing unit 3 using the same screen, mesh, and printing parameters as with pattern 1. Printing of pattern 3 was performed with UV Henkel/Acheson Electrodag 452SS dielectric ink using MAXI rotary screen printing unit 1. Electrodag PF455B ink was tested also. Gallus GV screen mesh 200 was used in printing of dielectric patterns. Printing speed was $2 \mathrm{~m} / \mathrm{min}$, and UV dryer was used for dielectric inks sintering. Two layers of dielectric pattern were printed consecutively in order to eliminate pin holes in dielectric pattern. Finally, pattern 4 was printed using the same unit, screen, ink, and printing parameters as with pattern 1 .

Continuous wiring board pattern printed roll for LED lighting system is shown in Fig. 4.

In principle, continuous printed wiring board can be several hundred meters long. Basic LED lighting element size of $17 \mathrm{~cm}(\mathrm{~W}) \times 20 \mathrm{~cm}(\mathrm{~L})$ was designed to contain $49 \mathrm{mid}-$ power LED components, type LUXEON 3535L, and seven current regulators, type NSI45030A. Basic element electrical system consisted of seven LEDs in series and seven LED series in parallel. Each LED series was equipped with twopin current regulator limiting the LED driving current to $25 \pm$ $0.5 \mathrm{~mA}$, when supply voltage varies from 21 to $31 \mathrm{~V}$. Nominal supply voltage of 24 VDC was designed to be used to drive the LEDs in the basic element. LEDs and current regulators were assembled on printed PET substrate using EVO 2200 automatic R2R bonding machine shown in Fig. 5.

Main specifications of EVO 2200 automatic bonding machine are listed as follows:

- Automated component assembly and bonding of various types of components on flexible substrates in continuous 200-mm width WEB in Stop \& Go process

- Work area size: $200 \mathrm{~mm}$ (width) $\times 300 \mathrm{~mm}$ (length)

- Die attached, flip chip, multichip: chip size down to $100 \mu \mathrm{m}$

- Standard SMD component attached
Fig. 6 Assembled LED lighting demonstrator containing 98 pieces of LEDs, type 3535L, and 14 driving current regulators, type NSI45030A: LEDs off (above) and LEDs on (below)
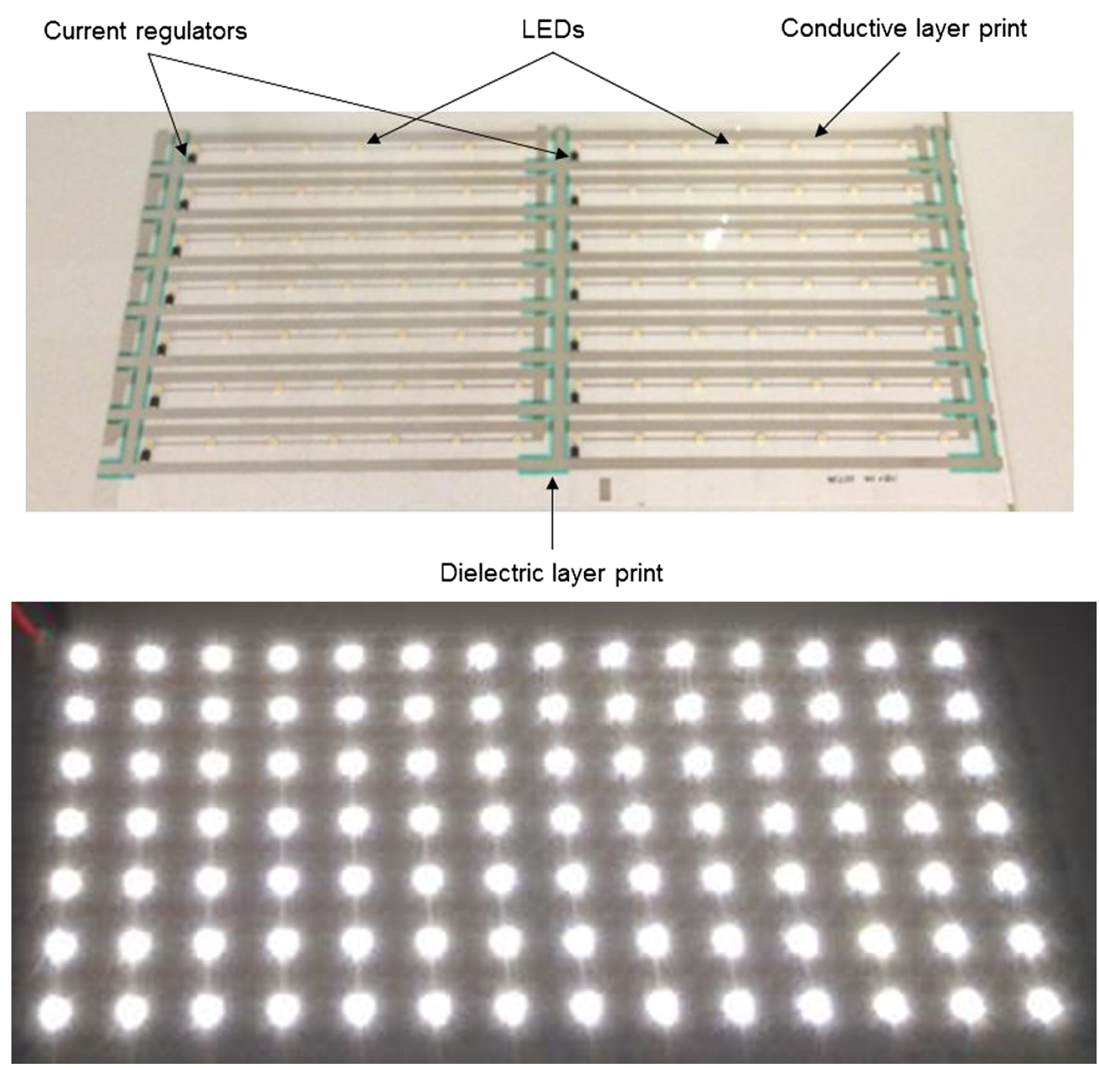
- Flex (solar cells, thin batteries, straps, etc.) size up to $100 \mathrm{~mm} \times 100 \mathrm{~mm}$

- Adhesives dispensing and stamping (ICA, ACA, NCA)

- Adhesive curing by thermo-compression and UV

- Highest accuracy $\pm 7 \mu \mathrm{m}$ at $3 \sigma$

- Die pick from wafer (max size $8^{\prime \prime}$ ), waffle pack, gel pack

- Device bonding on continuous WEB, sheet substrate, lead frame, wafer

- Individual process parameters for each interconnect

EVO maximum working area is $200 \mathrm{~mm} \times 300 \mathrm{~mm}$ area, but longer assembly layouts can be also handled by dividing the program to several parts. Web total length, however, can be several hundred meters long, and the machine can perform assembly to the total length of web, when the devices are small or flexible enough. Bonding of devices and components can be implemented by adhesive using isotropic conductive adhesive (ICA), anisotropic conductive adhesive (ACA), and/ or non-conductive adhesive (NCA) dispensing and stamping and cured by thermo-compression or UV. Assembly programming was performed for basic element area in this case. Bonding of LEDs on the printed PET substrate of LED lighting system demonstrator was performed using silver micro particle ICA EPO-TEK H20E. Final bond line curing schedule was in $120^{\circ} \mathrm{C}$ and $15 \mathrm{~min}$.

Processed LED lighting system demonstrator shown in Fig. 6 consists of two basic elements containing 98 LEDs and 14 regulators. Size of the demonstrator is $19 \mathrm{~cm}(\mathrm{~W}) \times$

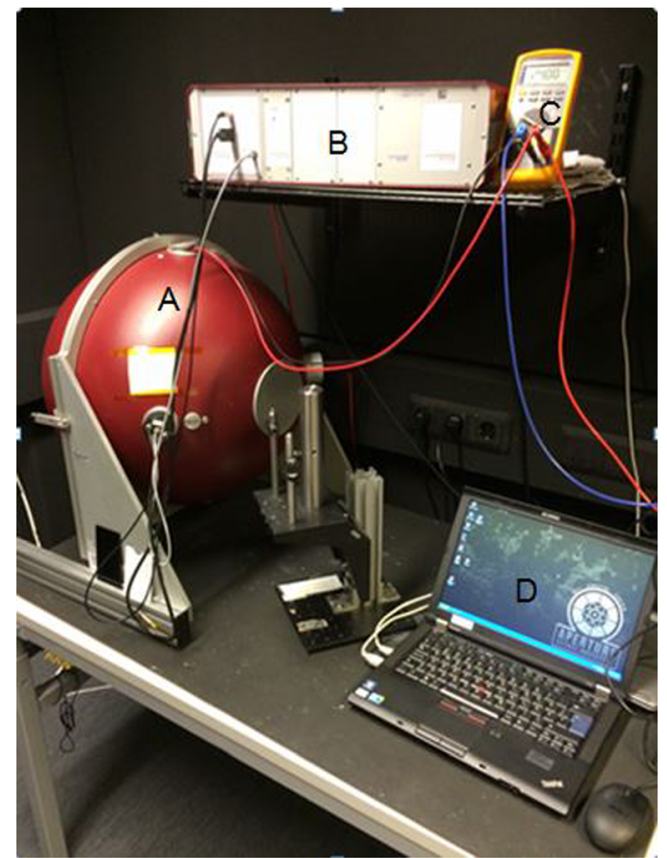

Fig. 7 Photometric characterization system used with LED lighting demonstrator, $A$ Gigahertz-Optik 0.5 -m diameter integrating sphere with luminous power sensor, $B$ spectrometer and electronics cabinet, $C$ digital multimeter for LED driving current monitoring, and $D$ laptop with Gigahertz-Optik measurement software

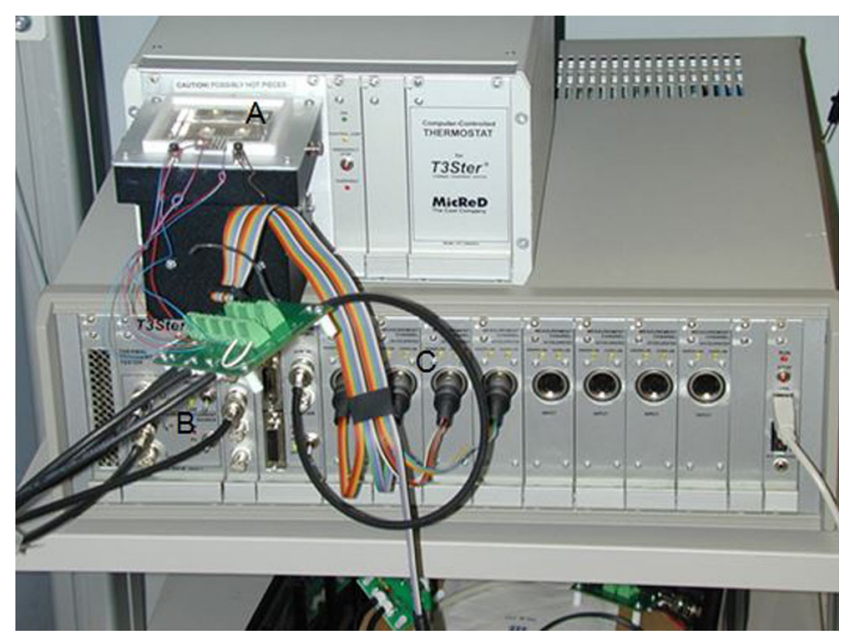

Fig. 8 T3Ster thermal measurement instrument used in the LED P/N junction temperature characterizations of the LED lighting demonstrator, $A$ calibration system, $B$ LED driving electronics, and $C$ four measurement channels

$40 \mathrm{~cm}$ (L). There can be multiple basic elements in the lighting system, and three, four, five, and six basic elements systems have been assembled and tested operationally, also. The number of basic elements in the lighting system is limited ultimately by the power supply capability to push adequate total current to the system with the required supply voltage level. Another limitation is produced by the characteristic conductivity of the printed wires decreasing the total efficiency of the lighting system.

\section{Characterization of lighting element demonstrator}

Total thickness of the lighting element was about $0.9 \mathrm{~mm}$. Lighting element photometric characterization was performed using $0.5-\mathrm{m}$ diameter integrating sphere shown in Fig. 7. Measured total illumination flux using $25 \mathrm{~mA}$ driving current for LEDs was $860 \mathrm{~lm}$ when using total electrical driving power of $8.4 \mathrm{~W}$. Electrical power to luminous power conversion efficiency of the demonstrator was $31 \%$ and luminous efficacy $102 \mathrm{~lm} / \mathrm{W}$. Element produced $460 \mathrm{~lx}$ illumination level measured by a Minolta illumination level meter at element's

Table 1 LED P/N junction temperatures with different LED driving currents

\begin{tabular}{ll}
\hline $\begin{array}{l}\text { LED driving } \\
\text { current }(\mathrm{mA})\end{array}$ & $\begin{array}{l}\text { LED P/N } \\
\text { junction } \\
\text { temperature }{ }^{\circ} \mathrm{C}\end{array}$ \\
\hline 0 & 25 \\
10 & 35 \\
20 & 45 \\
50 & 74 \\
100 & 120 \\
\hline
\end{tabular}


central axis at a distance of $1 \mathrm{~m}$. At a distance of $2 \mathrm{~m}$, measured illumination level was $110 \mathrm{~lx}$, respectively.

Temperatures of LEDs semiconductor $\mathrm{p}$-n junctions were measured using T3Ster measurement instrument (Fig. 8).

LED P/N junction temperatures measured with different LED driving currents are shown in Table 1.

From Table 1, we can see that about $120^{\circ} \mathrm{C}$ was measured with T3Ster thermal measurement instrument when driving the LEDs with $100 \mathrm{~mA}$ current. When using $100 \mathrm{~mA}$ driving current with LEDs, about $3400 \mathrm{~lm}$ illumination flux was achieved from the two-basic element lighting system generating illumination level of $440 \mathrm{~lx}$ at a distance of $2 \mathrm{~m}$ from demonstrator. A typical illumination level requirement for office lighting is $500 \mathrm{~lx}$ at the surface of a desktop. This lighting level can be achieved, when using three basic elements in lighting system and driving LEDs with $100 \mathrm{~mA}$ current.

When comparing achieved $3400 \mathrm{~lx}$ value to traditional light sources, we can notice that an equivalent emitted flux is achieved by using three 100-W light bulbs or three 18-W T8 fluorescent light tubes. We can conclude that luminosity power produced by the demonstrator is adequate for general lighting application. Thermal management of LED on PET foil can be improved by implementing special heat management structures in the LED bonding areas, such as thermal vias and slugs, to conduct the excess heat through the poor thermal conductivity PET material to the heat sink.

Accelerated environmental stress tests consisting of $500 \mathrm{cy}-$ cles from $-40 \ldots+80{ }^{\circ} \mathrm{C}$ in aging oven and $1000 \mathrm{~h}$ in $+60{ }^{\circ} \mathrm{C} /$ $95 \%$ RH climate chamber were performed without any failures. In addition, over 700 bending cycles using $20 \mathrm{~mm}$ bending radius were performed to test samples without any failures in their functionality, so bonding of LEDs were shown reliable according to these tests. When using bending radius smaller than $20 \mathrm{~mm}$, component failure typically occurred. The failure was caused by silver ink detachment from the PET substrate at the interconnection area due to a pulling force of a LED die when bending the structure. In such cases, cracks were formed across the conductive paths at the bonding area boundary and they were clearly visually noticeable by an optical microscope.

Achieved results demonstrate that thin, flexible, and large area high luminous flux lighting elements and systems can be processed based on printed plastic foil manufactured using $\mathrm{R} 2 \mathrm{R}$ printing and automatic bonding of LEDs and regulator components on that foil. Utilization of $\mathrm{R} 2 \mathrm{R}$ processing methods both in substrate manufacturing and performing assembly enables high throughput and cost-efficiency to produce large area LED lighting elements.

\section{Conclusion}

We have designed, processed, and characterized novel continuous and mass customizable LED lighting foil system. Lighting system PET substrate was processed utilizing R2R printing and $\mathrm{R} 2 \mathrm{R}$ automatic bonder with LEDs and current regulator components assembly on substrate using ICA.

This mass customizable lighting system is modular both along the printing machine direction (MD) and can also be cut in seven different widths of LED strips in printing machine cross direction (CD). This novel continuous and mass customizable LED lighting foil implementation enables cutting of variable size large area LED lighting elements all operating using 24 VDC.

According to the performed characterizations, LED lighting foil demonstrator containing two basic elements equipped with 98 LEDs was capable to produce total luminosity level of $860 \mathrm{~lm}$, when LEDs were driven using $25 \mathrm{~mA}$ current. Correspondingly, approximately four times higher luminosity of $3400 \mathrm{~lm}$ was achieved, when LEDs were driven using $100 \mathrm{~mA}$ current; $3400 \mathrm{~lm}$ luminosity power generated illumination level of $440 \mathrm{~lx}$ at a distance of $2 \mathrm{~m}$ from demonstrator. Integrating three or more basic elements used in the LED lighting demonstrator into the lighting system, we can achieve luminosity levels adequate for general lighting applications, such as $500 \mathrm{~lx}$ lighting level required in office lighting.

Thermal management of LED on PET foil can be improved by implementing special heat management structures in the LED bonding areas, such as thermal vias and slugs, to conduct the excess heat through the poor thermal conductivity PET material to the heat sink.

Utilization of R2R processing methods both in substrate manufacturing and performing assembly of lighting element enables cost-efficient and high-volume production of large area LED lighting elements.

Open Access This article is distributed under the terms of the Creative Commons Attribution 4.0 International License (http:// creativecommons.org/licenses/by/4.0/), which permits unrestricted use, distribution, and reproduction in any medium, provided you give appropriate credit to the original author(s) and the source, provide a link to the Creative Commons license, and indicate if changes were made.

\section{References}

1. D'Andrade B, Forrest S (2004) White organic light emitting devices for solid state lighting". Adv Mater 16:18

2. Blom P, van Mol T (2011) LEDs roll. PhysWorld 2011:32-35

3. van den Brand J et al (2008) Systems-in-foil - devices, fabrication processes and reliability issues. Microelectron Reliab 48:8-9

4. (2011) White Paper: OE-A Roadmap for Organic and Printed Electronics

5. Kim H, et al (2011) Unusual strategies for using indium gallium nitride grown on silicon (111) for solid-state lighting. Proc Natl Acad Sci USA 108

6. Kim Y et al (2012) Optimization of flexible substrate for COF (chip on flexible) LED packaging. Proc. 59th Electronic Components and Technology Conf, San Diego, pp 1953-60, May 2012 
7. Park S et al (2009) Printed assemblies of inorganic light-emitting diodes for deformable and semitransparent displays. Science 325:5943

8. Keränen $\mathrm{K}$ et al (2012) Hot laminated multilayer polymer illumination structure based on embedded LED chips. IEEE Trans Compon Packag Technol 2:12

9. Wenzl F et al (2014) Foil based optical elements for beam shaping and color homogenization of phosphor converted white LED sources. Proc SPIE 9190:91900A1-7

10. Mukish P (2011) LED cost and technology trends: how to enable massive adoption in general lighting. LED Forum, Lyon, 2011;December 7th

11. Fjelstad J (2011) Flexible circuit technology. 4th ed. Seaside: BR Publishing Inc.; p. 146-147

12. MacDonald W et al (2007) Latest advances in substrates for flexible electronics. J Soc Inf Display 15:12

13. van den Brand $\mathrm{J}$ et al (2011) Flipchip bonding of thin Si dies onto PET foils: possibilities and applications. Proc. 18th european microelectronics and packaging conf, Brighton, September 2011. art. 6142415
14. Fjelstad J (2011) Flexible circuit technology. 4th ed. Seaside: BR Publishing Inc., p. 149

15. van den Brand J, et al (2010) A. Flip chip bonding of ultrathin Si dies onto PEN/PET substrates with low cost circuitry. In: 3rd Electronic system-integration technology conference (ESTC), IEEE, p. 1-6

16. Chang M et al (2012) Reliability of high-power LED packaging and assembly. Microelectron Reliab 52:5

17. Li Y, Wong C (2006) Recent advances of conductive adhesives as a lead-free alternative in electronic packaging: materials, processing, reliability and applications. Mater Sci Eng $51: 1-3$

18. van den Ende D et al (2013) Large area flexible lighting foils using distributed bare LED dies on polyester substrates". Microelectron Reliab 53:12

19. Tapaninen O, et al (2014) Thermal management in flexible substrates for LEDs. IMAPS Nord Conf p. 1-6 